Vol. 1, No. 2, 2020, pp. 42-47

DOI: https://doi.org/10.2921/07essr55800

Contents lists available at Џournal IICET

Education and Social Sciences Review

ISSN: 2720-8915 (Print) ISSN: 2720-8923 (Electronic)

Journal homepage: https://jurnal.iicet.org/index.php/essr

\title{
Mini thermoforming semi-auto machine for teaching and learning
}

\author{
Mastura Binti Ibrahim ${ }^{1}$, Siti Aishah Binti Wahid ${ }^{2}$, Sullyfaizura Binti Mohd Rawi ${ }^{3}$ \\ ${ }^{123}$ Politeknik Sultan Mizan Zainal Abidin, Malaysia
}

\begin{tabular}{l}
\hline Article Info \\
\hline Article history: \\
Received Apr $13^{\text {th }}, 2020$ \\
Revised May $27^{\text {th }}, 2020$ \\
Accepted Jun $30^{\text {th }}, 2020$ \\
\hline
\end{tabular}

\section{Keyword:}

Mini thermoforming semi-auto machine

Learning and teaching

Stress test

\begin{abstract}
Mini Thermoforming Semi-Auto Machine is a product-making machine from heated plastic sheets. This machine uses a vacuum suction method to form a product that you want to produce. This machine is designed to help and facilitate learning and teaching matters in higher education institutions where the use of this machine can reduce costs especially maintenance costs if damaged. The size of the machine is $600 \mathrm{~mm} \times 500 \mathrm{~mm}$ which is one per fourth of the actual size in the plastic manufacturing factories. Some testing of machines and products is done. Among them is the test of lifting frame which shows the time taken for the upward movement is 4 seconds and 3.5 seconds to decrease. In addition, stress tests are also performed where the product can be perfectly formed when inhaled by vacuum. In terms of temperature the test is done by heating on the sheet or plastic sheets. The last test was made on the product, where the product was produced perfectly within 3 minutes and the temperature was $240^{\circ} \mathrm{C}$. With the creation of this Mini Thermoforming SemiAuto Machine, it is hoped that the learning and teaching process in institutions of higher learning will work better as this machine provides comfort in terms of size and prioritizes the safety of lecturers and students and is able to produce products in a short time.
\end{abstract}

(C) 2020 The Authors. Published by IICET.

This is an open access article under the CC BY-NC-SA license

(https://creativecommons.org/licenses/by-nc-sa/4.0

\section{Corresponding Author:}

Mastura Binti Ibrahim

Politeknik Sultan Mizan Zainal Abidin, Malaysia

Email: mastura.ibrahim@psmza.edu.my

\section{Introduction}

Thermoforming is the process of heating and reshaping plastic sheet and film materials has been in use for plastics industry. Thermoforming is commonly used for food packaging, but has many applications from plastic toys to aircraft windscreens to cafeteria trays. This process also used for industrial products including signage, housings, and hot tubs (Klein, 2009). Thin-gauge (less than 0.060 inches) sheets are mostly used for rigid or disposable packaging, while thick-gauge (greater than 0.120 inches) sheets are typically used for cosmetic permanent surfaces on automobiles, shower enclosures, and electronic equipment. Thermoforming machine is a manufacturing process where plastic sheet is heated to a pliable forming temperature formed to a specific shaped in a mold and trimmed to create a usable product. (Throne, 2002). The film when referring to thinner gauges and certain material types is heated in an oven to high-enough temperature that permits it to be stretched into or onto a mold and cooled to a finish shape its simplified version is vacuum forming. Thermoforming can be accomplished using pressure and heat (pressure forming), vacuum and heat (vacuum forming) and thin gauge thermoforming. Generally the thermoforming machine consist of heating system, forming press, vacuum system and sheet handling system. 


\section{Discussion}

\section{Types of thermoforming machine}

Thermoforming machine has three types which depend on pressure, such as vacuum forming, pressure forming and match die forming. Table 1 showed the three types of thermoforming machine and its process that has been designed.

Table 1. Types of Thermoforming and Process (Hassan, Ghazali, Jaafar, \& Ismail, 2016)

Types and Diagram

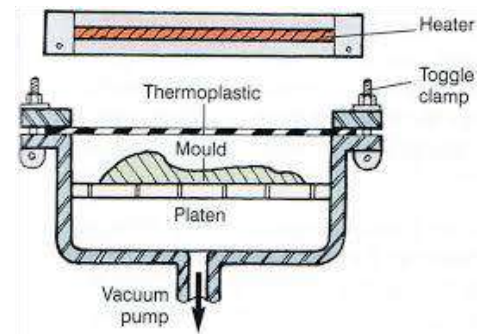

Figure 1 Vacuum Forming Process

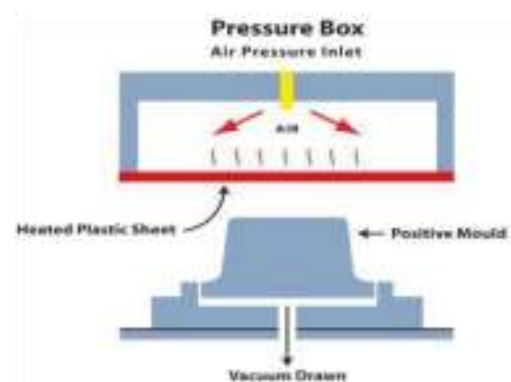

Figure 2 Pressure Forming Process

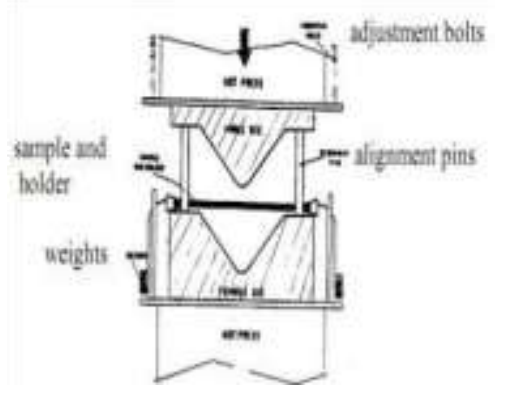

Figure 3. Match die forming process

\section{Process}

Vacuum forming is a plastic thermoforming process involving forming thermoplastic sheets into threedimensional shapes through the application of heat and pressure. In lay terms, Vacuum forming refers to all sheet forming methods including drape and forming, which is one of the most popular. Basically during vacuum forming, the plastic material is heated until it takes on desired shapes.

This process is similar to vacuum forming, except addition of pressure, which pushes the sheet into the shape of the mould. This process is mainly used for parts requiring styling and aesthetic qualities because pressure forming creates greater details, allowing for textured surfaces, undercuts and sharp corner which are not as easily created with vacuum forming.

In this process, both halves of the part are formed by moulds with no vacuum and air pressure. The sheet is heated until it is soft then both moulds halves clamp together to form the parts used with parts that do not have large draws.

Only thermoplastics sheet can be processed by this method. There are some important section in vacuum thermoforming machine. This section including heating section, forming section, cutting section, stacking section and waste winding section. All of these section commonly is the major causes that lead to the parameter for the thermoforming machine. In order to produce high quality product, all of the section must be ensured so that we could reduce the parameter while producing a high quality product (Raja, Littlewood, Munyombwe, \& Bubb, 2013).

\section{Mini thermoforming design}

The main objective of project is to design and fabricate mini thermoforming semi-auto for teaching and learning in education institution. Thermoforming machine is one of the major machine that is always been used by the institution for teaching and learning especially for those who taking plastic and manufacturing course. Based on the real thermoforming machine, their size and capacity is bigger and the dimensions is from $1.500 \times 1.200 \mathrm{~mm}$ up to $3.000 \times 2.000 \mathrm{~mm}$. Hence, the bigger size of the machine it makes it harder to care 
since the machine need expertise services to dodge the machine from any damage. Therefore, the machine that will be produced will be able to reduce all the problems faced above. The machine processing can be designated easily even the parameters for this machine is not like a real machine. The design of Mini Thermoforming Semi-Auto Machine was generated in Figure 4.
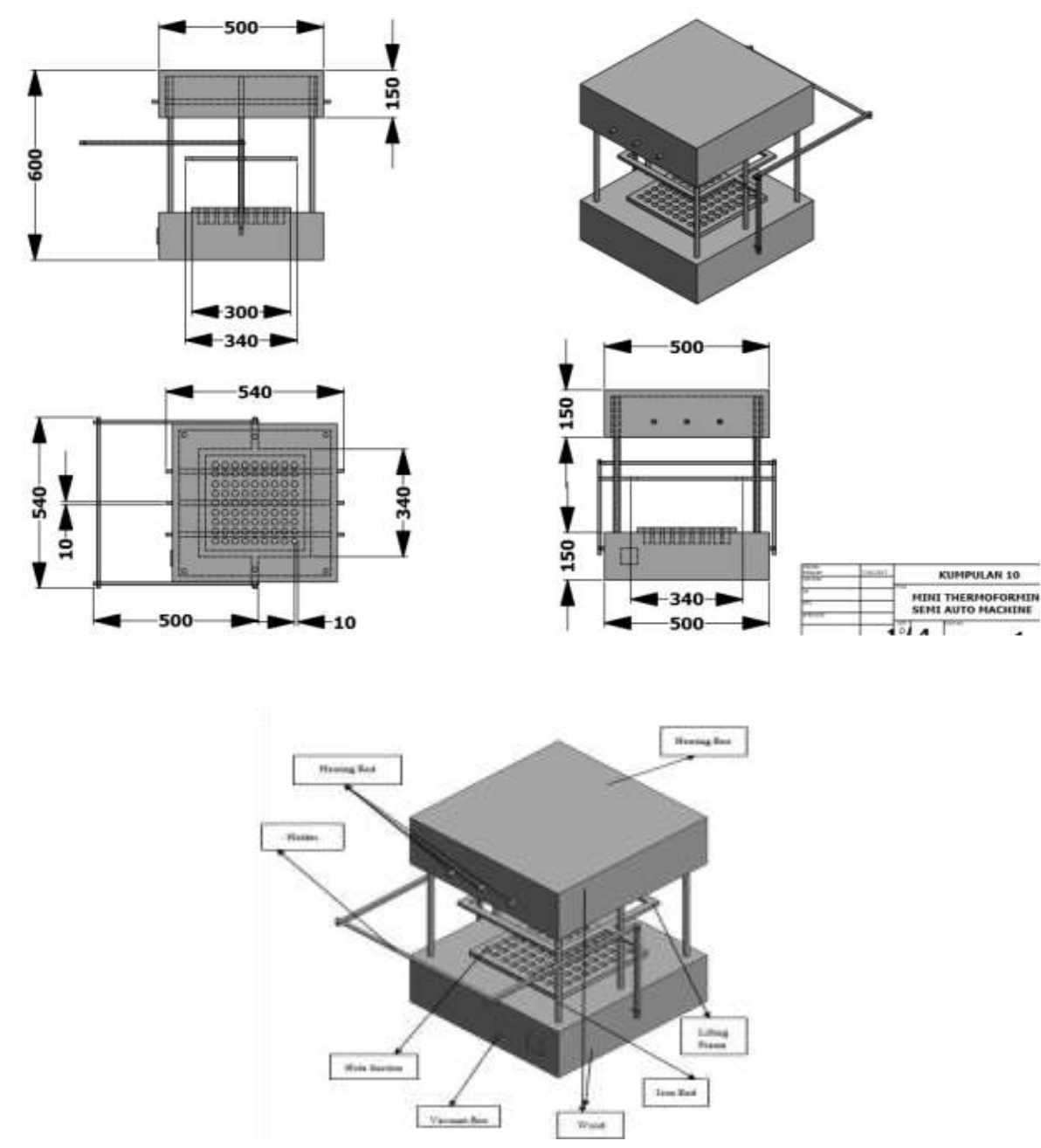

Figure 4. Design of mini thermoforming semi-auto machine

Thermoforming Testing

In this project there are four types of testing have been performed on Mini Thermoforming Semi-Auto machines shown in Figure 5. The first test is carried out on the lifting frame followed by testing at pressure, temperature and final product.

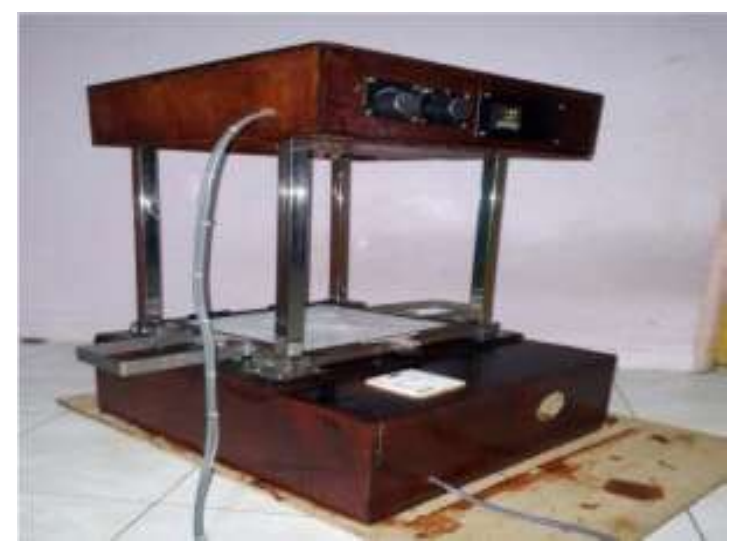


Figure 5. Mini thermoforming semi-auto machine

\section{Lifting frame testing}

Testing is done on the lifting frame where it is tested in terms of time for it to fall and rise. The Lifting frame is used for movement of plastic sheet up and down in the process of produced the product. Base on Table 2, the result for lifting frame test shown, the time for it rise is 4 seconds and time for it fall is 3.5 seconds. This is similar to the lifting frame that used in industrials.

Table 2. The data obtained from lifting frame result

\begin{tabular}{ccc}
\hline Trial & Time for Rise & Time for Fall \\
1 & 4 seconds & 3.5 seconds \\
\hline
\end{tabular}

\section{Temperature testing}

Based on Table 3, it can be seen that the product cannot be perfectly formed when using different temperatures. Trial 1 shows the product is not imperfect formation. Temperature used in this trial is $150^{\circ} \mathrm{C}$ with 3 minutes. The product cannot be perfectly formed because plastic sheets cannot be heated adequately. Trial 2 used $200^{\circ} \mathrm{C}$ temperature with 3 minutes and observation for the product is imperfect formation. The causes of this trial is same with trial 1 , plastic sheets cannot be heated adequately. If the temperature of plastic sheet is not accurate, there will be much more flaws in plastic product (Du, Chen, \& Liang, 2011). Lastly, the product can be perfectly formed in trial 3 with $240^{\circ} \mathrm{C}$ and 3 minutes. This is because the plastic sheets can be heated with $240^{\circ} \mathrm{C}$ temperature until softened point achieved. In the process of plastic forming, temperature control have a great influence on quality of plastic forming.

Table 3. the data obtained from temperature results

\begin{tabular}{cccc}
\hline Trials & Time (minutes) & Temperature $\left.\mathbf{~}^{\circ} \mathbf{C}\right)$ & Observation \\
1 & 3 & $150^{\circ} \mathrm{C}$ & Imperfect Formation \\
2 & 3 & $200^{\circ} \mathrm{C}$ & Imperfect Formation \\
3 & 3 & $240^{\circ} \mathrm{C}$ & Perfect Formation \\
\hline
\end{tabular}

\section{Pressure testing}

Based on the results noted in Table 4, it can be seen trial 1 and trial 2 get a perfect formation for products result. This is because the depth of the mold used in this trials is lower than 2.0 centimeter. For third and fourth trial, the product cannot be formed with perfectly because the mold used is above $2.5 \mathrm{~cm}$. The results proved that the pressure of this machine is strong for produced the product with mold that have a depth lower than $2.0 \mathrm{~cm}$.

Table 4. The data obtained from pressure results

\begin{tabular}{ccc}
\hline Trials & Depth & Observation \\
1 & $0.5 \mathrm{~cm}$ & Perfect Formation \\
2 & $1.5 \mathrm{~cm}$ & Perfect Formation \\
3 & $2.5 \mathrm{~cm}$ & Imperfect Formation \\
4 & $3.0 \mathrm{~cm}$ & Imperfect Formation \\
\hline
\end{tabular}

Formation product testing

Table 5. The formation of product testing

\begin{tabular}{lll}
\hline Trial Minutes & \multicolumn{1}{c}{ Result } \\
$1 \quad 3$ minutes & $\begin{array}{l}\text { The perfect formation occurs at } 3 \text { minutes, } \\
\text { because the level of softness of the desired } \\
\text { plastics sheet is achieved. }\end{array}$ \\
$2 \quad \begin{array}{l}\text { Product produces in } 5 \text { minutes level, the product is not perfectly } \\
\text { formed as the plastic sheet exceeds the } \\
\text { required softness level. }\end{array}$
\end{tabular}




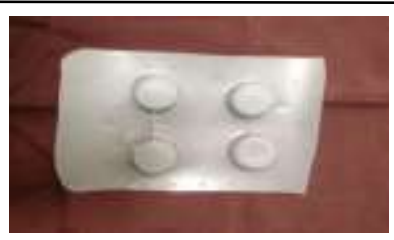

3 Product produced in 7 minutes

4
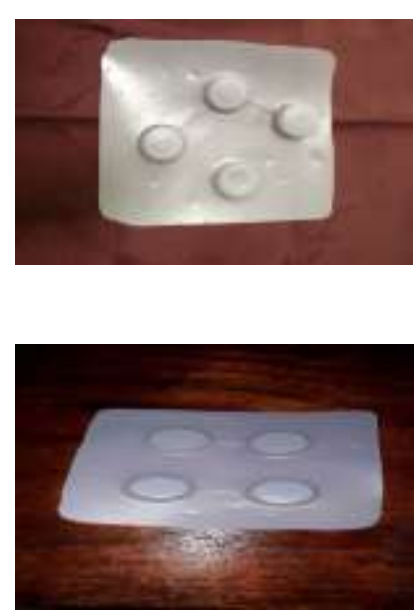

At 7 minutes level, the resulting product is also imperfect and has a defect.
At 10 minutes level, the product shows cannot be perfectly formed because the plastics reached the level of liquid.

\section{Final product testing}

Based on Table 5, it can be seen trial 1 with temperature of $240^{\circ} \mathrm{C}$ and 3 minutes gives perfect formation compared to trial 2, 3 and 4. This is due to the plastic sheet being melted when it goes beyond the 3 minutes and the product formed has a defective or imperfect. The temperature of this machine have been set to $240^{\circ} \mathrm{C}$. When temperature $250^{\circ} \mathrm{C}$ and above can reached a melting point.

Table 5. The data obtained from final product results

\begin{tabular}{cccc}
\hline Trial & Temperature $\left({ }^{\circ} \mathbf{C}\right)$ & Time & Observation \\
1 & $240^{\circ} \mathrm{C}$ & 3 Minutes & Perfect Formation \\
2 & $240^{\circ} \mathrm{C}$ & 5 Minutes & Imperfect Formation \\
3 & $240^{\circ} \mathrm{C}$ & 7 Minutes & Imperfect Formation \\
4 & $240^{\circ} \mathrm{C}$ & 10 Minutes & Imperfect Formation \\
\hline
\end{tabular}

From Table 5, that perfect formation occurs at 3 minutes time is because the level of softness of the desired plastic sheet is achieved when heating on the plastic sheet is done for 3 minutes. At 3 minute levels, the product is perfected and no defects occur. Table 6 shows the product that produced in 3 minutes. At 5-minute level, the product is not perfectly formed as the plastic sheet exceeds the required softness level and this causes the product to have defects. At 7-minute level, the resulting product is also imperfect and has a defect same as with 5 minutes.

\section{Conclusion}

Mini Thermoforming Semi-Auto Machine is designed to help and facilitate learning and teaching matters in higher education institution. The size of the machine is $600 \mathrm{~mm}$ x $500 \mathrm{~mm}$ which is one per fourth of the actual size in the plastic manufacturing factories. Test performance was carried out on the fabricated Mini Thermoforming Semi-Auto Machine. The best temperature is $240^{\circ} \mathrm{C}, 3$ minutes for the perfect product. This machine also can be used learning and teaching process of manufacturing plastic product. By producing the mini thermoforming semi-auto machine, it gives the advantages in terms of easy care since the machine dimensions is smaller. Plus, the machine will be easily to be handle for the new learner. 


\section{References}

Du, C., Chen, S., \& Liang, X. (2011). Application of Fuzzy theory in temperature control system of thermoforming machine. Procedia Engineering, 15, 639-643.

Hassan, N. R. N., Ghazali, F. A. M., Jaafar, A. A., \& Ismail, N. M. (2016). Preparation of polypropylene thermoplastic container via thermoforming process. Paper presented at the IOP Conference Series: Materials Science and Engineering.

Klein, P. (2009). Fundamentals of plastics thermoforming. Synthesis Lectures on Materials Engineering, 1(1), 1-97.

Raja, T. A., Littlewood, S. J., Munyombwe, T., \& Bubb, N. L. (2013). Wear resistance of four types of vacuum-formed retainer materials: a laboratory study. Angle Orthodontist, 84(4), 656-664.

Throne, J. L. (2002). Thermoforming. Encyclopedia of Polymer Science and Technology. 